\title{
Síndrome de Burnout: Relações com Comprometimento Afetivo entre Gestores de Organização ESTATAL ${ }^{\text {I }}$
}

\section{BURNOUT SYNDROME: RELATIONSHIP WITH AFFECTIVE ORGANIZATIONAL COMMITMENT AMONGST MANAGERS ON STATE-OWNED ORGANIZATION}

ROSA MARIA DE S. ALBUQUERQUE BARBOSA Mestre em Administração, Universidade de Brasilia. Analista de Planejamento Estratégico da Centrais Elétricas do Norte do Brasil S/A - Eletronorte. SHIN, QI 9, conjunto 10, casa 21 - Brasília-DF-CEP 71515-300

E-mail: rosa@eln.gov.br

TOMÁS DE AQUINO GUIMAR ÃES Professor Adjunto. Doutor. Universidade de Brasília, Departamento de Administração. SQN 1 16, Bloco I, Apto. 305 - Brasília - DF - CEP 70773-090 E-mail: tomas@unb.br

I Os autores agradecem as críticas à versão preliminar, realizadas por avaliadores anônimos da Revista de Administração Mackenzie, que muito contribuíram para o aperfeiçoamento do artigo 


\section{RESUMO}

Esta pesquisa envolveu dois conceitos centrais e a tentativa de articulá-los teórica e empiricamente: síndrome de burnout e comprometimento organizacional afetivo. Foram aplicados 249 questionários, contendo escalas padronizadas de cinco pontos, tipo Likert, e realizadas i 6 entrevistas, apoiadas em roteiros semi-estruturados, entre gestores da Eletronorte. Formulou-se a hipótese de que os respondentes apresentariam comportamentos típicos de burnout e de que haveria uma relação positiva entre esta variável e comprometimento afetivo. Foram realizadas análises inferenciais e identificou-se, entre os respondentes, nível moderado de burnout nos fatores exaustão emocional, despersonalização e baixa realização pessoal, sendo que $27,7 \%$ dos pesquisados apresentaram índices altos ou moderados nos três fatores da síndrome, predominando o fator baixa realização pessoal; 6I, $8 \%$ e 36,I4\% dos respondentes apresentaram níveis elevado e moderado, respectivamente, de comprometimento afetivo. A hipótese foi confirmada quanto à presença de burnout e rejeitada no que se refere à relação positiva entre a síndrome e comprometimento. Os resultados podem ser úteis para a compreensão de fenômenos pouco explorados no campo do comportamento organizacional, em especial entre gestores que atuam em organizações em fase de transformação.

\section{PALAVRAS-CHAVE}

Síndrome de burnout; Comprometimento organizacional afetivo; Organização estatal.

\section{ABSTRACT}

This research encompasses two main concepts and aimed to analyse them both theoretical and empirically: burnout syndrome and affective organisational commitment. 249 five-point standardised Likert-scale questionnaires were filled out and I6 interviews, supported by semi-structured schedules were undertaken with Eletronorte managers. The research hypothesis was 
that these managers would have typical burnout behaviour and a positive relationship between this syndrome and attitudinal commitment would be find. Inferential analyses were done and medium level of burnout syndrome on the emotional exhaustion, depersonalisation and low personal accomplishment were identified. $27,7 \%$ of the managers presented medium or high levels on the three syndrome factors, stressing the low personal accomplishment factor; $61,8 \%$ and $36, \mathrm{I} 4 \%$ of the research participants showed high and medium levels, respectively, of attitudinal commitment. The hypothesis was accepted upon the burnout syndrome, but rejected on the positive relationship between that syndrome and commitment. The results can be useful to understand factors less explored on the organisational behaviour field, especially amongst managers that work on organisations which are on changing process.

\section{KEYWORDS}

Burnout syndrome; Affective organizational commitment; State-owned organization.

\section{INTRODUÇÃO}

Burnout pode ser entendido como uma reação à tensão emocional, que resulta na redução da motivação para o trabalho e na inabilidade progressiva de indivíduos para mobilizar interesses e habilidades, visando à consecução de objetivos organizacionais. Apesar de a grande maioria das pesquisas sobre a síndrome de burnout estar focada em profissionais que atuam em setores como educação, saúde, segurança e outras ocupações que implicam contatos com pessoas que necessitam de ajuda, há estudos que indicam que seus sintomas também se manifestam entre gestores. A respeito de burnout entre gerentes, veja Buick e Thomas (200I). O comprometimento organizacional, entendido como resultante de um processo de identificação e envolvimento do indivíduo com uma organização, tem sido estudado nas mais variadas organizações e ocupações. Este trabalho descreve a relação entre burnout e comprometimento organizacional afetivo entre gestores da Eletronorte.

Os estudos realizados sobre liderança ainda não permitiram formar um consenso entre os pesquisadores interessados na questão. Essa constatação se baseia na complexidade do tema e nas diversas abordagens e perspectivas que vem recebendo de estudiosos ao longo do tempo. Realizar pesquisa sobre liderança parece exigir mais do que tentar compreender o fenômeno e ver como ele se manifesta. Um dos focos de estudo de liderança procura investigar como o líder se sente e 
como o seu sentimento interfere na sua relação com os membros de sua equipe. A literatura sobre liderança mostra ainda que o seu exercício não está, necessariamente, associado com o exercício de um cargo gerencial, ou seja, um gerente ou gestor pode não ser um líder e vice-versa. Entretanto, como o presente estudo se refere especificamente ao trabalho de gestores, os termos líder, gerente e gestor são utilizados, neste trabalho, como sinônimos.

A habilidade de gerenciar mudanças com êxito parece ser o grande desafio do líder contemporâneo. Ao gestor cabe, portanto, encontrar alternativas para gerenciar tais mudanças, adaptando-se às novas realidades organizacionais, que, apesar de representarem novas oportunidades, representam também ameaças para as organizações. Os empregados das empresas, quando ameaçados na estabilidade do emprego ou mesmo na forma de conduzir suas atividades, demandam gestores que inspirem confiança na definição dos rumos a serem seguidos. Demandam por líderes que sejam capazes de reduzir a incerteza subjetiva de suas existências no trabalho, que confiram um significado a suas atividades cotidianas e que estabeleçam uma compreensão daquilo que estão fazendo e para onde estão indo. Percebe-se, entretanto, que nem sempre os gestores estão preparados para responder às demandas de suas equipes, o que pode resultar em conflitos desgastantes para os empregados, para os próprios gestores e, como não poderia deixar de ser, para a organização.

O setor elétrico brasileiro, no qual se insere a organização em que a presente pesquisa foi realizada, vem passando, desde I995, por um processo de transformações institucionais que envolveu cisões, fusões, transferências de empresas estatais para capitais privados e, finalmente, aprovação de um novo modelo para o setor, com o encerramento do processo de privatização, mas com novos objetivos e papéis. Esse processo demanda uma preparação cuidadosa das organizações e das pessoas para que essas mudanças sejam implementadas com sucesso, isto é, com um mínimo de efeitos colaterais.

Por se tratar de uma empresa estatal, a Eletronorte, organização na qual se realizou esta pesquisa, convive com as restrições burocráticas inerentes ao modelo de gestão de organizações públicas. Isso implica que seu corpo gerencial possui pouca autonomia para gerenciar suas equipes. Aos gestores não é permitido, por exemplo, premiar os empregados com desempenho acima da média, e dificuldades são impostas na decisão do gestor sobre a adoção de processos de recuperação dos que apresentam desempenho insuficiente. O processo de transformação pelo qual a organização vem passando pode acarretar frustrações e insatisfações no ambiente do trabalho, que resultem em estresse, desmotivação e, também, na síndrome de burnout, como será explorado adiante. Isso porque ao se verem chamados a desenvolver seus papéis de facilitadores do desenvolvimento, da educação, da motivação de seus empregados, e, ao mesmo 
tempo, não encontrando suporte da organização para implementar as mudanças necessárias ou ainda sendo compelidos a operacionalizar alterações bruscas, os gestores podem apresentar a síndrome de burnout.

Tendo como tema central a síndrome de burnout, buscou-se, com esta pesquisa, relacioná-la com o comprometimento organizacional afetivo e identificar como se dá essa relação entre gestores da Eletronorte, organização que se encontrava, na época da realização da pesquisa, segundo semestre de 2000 , preparando-se para ser transferida para o setor privado e, portanto, em fase de declínio. Nas demais seções são discutidos os conceitos associados a cada um desses construtos, os métodos e as técnicas utilizadas na pesquisa, bem como a análise e discussão de seus resultados. Ao final, são apresentadas as principais conclusões e recomendações decorrentes do trabalho.

\section{SÍNDROME DE BURNOUT: - CONCEITO E SUA EVOLUÇÃO}

Os estudos sobre a síndrome de burnout vêm se desenvolvendo mais especificamente a partir da década de I970. No Brasil, um dos primeiros estudos sobre o assunto foi realizado por Tamayo (I997), que procurou identificar a presença dos fatores da síndrome entre profissionais de dois hospitais da rede pública e analisar a relação entre os referidos fatores e os pólos axiológicos organizacionais. Codo (I999) pesquisou a existência da síndrome em 39.000 professores de todo o Brasil. Esses estudos sinalizam que essa síndrome se desenvolve, em ambientes de trabalho, como reflexo de um grande número de novas tendências sociais, políticas, econômicas, filosóficas, profissionais e intelectuais. As contínuas mudanças poderiam estar contribuindo diretamente para aumentar os níveis de estresse e de frustração no ambiente de trabalho das pessoas. Em complemento, a desintegração dos ambientes familiares, institucionais e comunitários também pode estar contribuindo para o surgimento da síndrome de burnout, uma vez que os diferentes valores pessoais podem gerar gradativa redução do sentimento de confiança entre as pessoas.

Conforme Tamayo (I997), o termo burnout foi proposto, pela primeira vez, em I974, por Herbert Freudenberger, psicólogo clínico, familiarizado com o estresse apresentado por empregados de instituições sociais, como casas de saúde. O primeiro estudo empírico sobre o assunto foi publicado por Christina Maslach em I976, apoiado em pesquisas desenvolvidas a partir de I973, com o objetivo de identificar as dimensões sociais e psicológicas da síndrome de burnout. A autora pretendia identificar os aspectos estressantes comuns em ambientes de trabalho de profissionais da saúde e identificar o que esses profissionais 
faziam para conviver com esses aspectos, que técnicas específicas utilizavam para superar o estresse e que efeitos causavam quando buscavam se prevenir.

Segundo Kamis (1982), embora o termo burnout seja definido literalmente como "falhar", "colocar fora" ou "tornar-se exaurido por excessivas demandas de energia, resistência ou recursos”, seu sentido é mais abrangente ao ser relacionado com uma síndrome indesejável que se manifesta como reação a situações estressantes de trabalho. Farber (I99I, apud CODO, I999:240) define burnout como uma "síndrome do trabalho, que se origina da discrepância da percepção do indivíduo entre esforço e conseqüência, percepção esta influenciada por fatores individuais, organizacionais e sociais".

Do ponto de vista legal, a síndrome de burnout surge no Brasil com a publicação, no Diário Oficial da União, em I8.06.I999, do Regulamento da Previdência Social, alterado nos seus anexos. Na especificação de doenças e de agentes etiológicos ou fatores de risco de natureza ocupacional, prevista no artigo 20 da Lei no 8.213/9I, essa síndrome foi acrescentada na seção que trata dos "transtornos mentais e do comportamento relacionados com o trabalho". Em estudo da legislação previdenciária, Sabatovski e Fontoura (200I:289) também definem a "sensação de estar acabado" como síndrome de burnout, ou síndrome do esgotamento profissional.

A síndrome de burnout vem sendo associada aos seguintes componentes: exaustão emocional, despersonalização e diminuição da realização pessoal. Embora possam ser estudados separadamente, o termo burnout, costumeiramente, vem sendo usado, pela maioria dos pesquisadores, para se referir ao conjunto dos três fatores de acordo com constatação apresentada no estudo de Jackson et al. (i986). Maslach, ao pesquisar a síndrome de burnout, elaborou o Maslach Burnout Inventory (MBI), para ser utilizado como instrumento de sua mensuração. Lee e Ashforth (1997) argumentam que o MBI é o instrumento mais amplamente utilizado nas pesquisas que abordam burnout, porque permite determinar a distinção entre os seus sintomas e verificar se estão vinculados a outras variáveis do trabalho. Cordes e colaboradores (I997) investigaram a relação entre burnout e variáveis críticas que são teoricamente associadas ao referido fenômeno em grupos diferenciados de trabalho e consolidaram a melhor representatividade dos três fatores apresentados no modelo de Maslach.

$\mathrm{Na}$ análise desenvolvida por Lee e Ashforth (I997), investigando a correlação das três dimensões do MBI, entre 58 pesquisas que trataram do assunto, foram encontradas consistências no modelo desenvolvido por Leiter (I986) no que concerne à associação das três dimensões do MBI com várias combinações de atitudes no trabalho. Os autores concluíram que os fatores exaustão emocional e despersonalização estão mais fortemente associados com intenções de modificações e mudança de acionistas de empresas ou mudança de comando (passando para o controle de outros), e a comprometimento organizacional, 
enquanto estão fracamente associados com confronto de controle e de autoridade. Advertem, entretanto, que não está suficientemente claro se essa baixa correlação reflete a pouca existência de comportamento competitivo ou se houve uma pequena efetividade de estudo e subseqüente abandono. Em qualquer caso a ausência de uma reação efetiva de competição pode ter servido para reforçar sentimentos de desamparo e fracasso (LEE e ASHFORTH, I997). Contrariamente, a baixa realização pessoal está fortemente relacionada à competição por comando, sugerindo que a reação de um foco de problema e uma auto-avaliação positiva podem ser mutuamente reforçados (LAZARUS e FOLKMAN, I984, apud LEE e ASHFORTH, I997).

Zohar (I997) argumenta que, embora a literatura freqüentemente apresente a síndrome de burnout como formada pela exaustão emocional, despersonalização e diminuição da realização pessoal, a exaustão emocional constituiria o fator primário ou talvez o único sintoma que poderia ser discriminado e validado como burnout. Para melhor compreensão da alternativa apresentada, o autor examina alternativas de mensuração do acréscimo de demandas de trabalho, relacionados com a síndrome de burnout, mais especificamente com a exaustão emocional. Com vistas a dar suporte ao estudo, apresenta a argumentação de que a referida síndrome se desenvolve quando os recursos físicos ou emocionais são esgotados, como um resultado que excede a renovação, dando origem a uma redução de capacidade e a um modelo de fadiga. Assim, para o autor, os precursores de fadiga e de exaustão emocional poderiam ser os mesmos. Densten (200I), por outro lado, testou as propriedades psicométricas do Maslach Burnout Inventory em pesquisa realizada com uma amostra de 480 gestores de uma organização policial australiana e sugere a existência de cinco fatores. Esse autor, após realizar análises fatoriais exploratória e confirmatória, informa que o fator exaustão emocional subdivide-se em aspectos psicológicos e somáticos, o fator diminuição da realização pessoal desdobra-se nas visões auto e hetero do fator, enquanto o fator despersonalização permanece como no modelo original.

Os sintomas ou manifestações mais freqüentemente identificados nas pessoas com burnout são: sintomas físicos, como dores de cabeça, enjôos, dores musculares (especialmente na parte inferior das costas), problemas sexuais, distúrbios do sono, perda do apetite, falta de ar, fadiga crônica (SCHAUFELLI e BUNK, I996); sintomas comportamentais, por exemplo, hiperatividade, explosão emocional violenta, tendência ao aumento do consumo de estimulantes e abuso de substâncias tóxicas (ARCHES, I99I); manifestações sociais, como busca do auto-isolamento, e pouco envolvimento com colegas de trabalho e clientes (MASLACH, I978); manifestações atitudinais, na forma de desumanização, insensibilidade, distanciamento, indiferença e cinismo com relação aos colegas e clientes (TAMAYO, I997); outras manifestações no trabalho, como intenção 
de abandonar o emprego, turn over, absentismo, baixa produtividade, atrasos, acidentes, roubos e negligência (SCHAUFELLI e BUNK, I996). No campo organizacional mais amplo foram encontradas manifestações de burnout como papel conflitivo, papel ambíguo, sobrecarga do trabalho, clima organizacional, tomada de decisões, suporte social (BYRNE, I993).

Na seção seguinte são discutidos os conceitos e as características do construto comprometimento no trabalho, com ênfase para o comprometimento organizacional afetivo, de modo que permita, em seguida, a discussão a respeito da sua relação com burnout.

\section{COMPROMETIMENTO NO TRABALHO E COMPROMETIMENTO ORGANIZACIONAL AFETIVO}

O comprometimento no trabalho, a exemplo do que ocorre com burnout, é um conceito "em construção" no campo do comportamento organizacional. Entendido como um construto que busca traduzir e explicar a relação existente entre o empregado, seu trabalho e a organização, o comprometimento tem se apresentado como uma vantagem competitiva para as empresas e, por isso, a identificação de sua existência tem se tornado foco de inúmeras pesquisas nos últimos anos. Seus sintomas podem estar relacionados a distintos padrões de comportamento, como se descreve a seguir.

Conner (I995) argumenta que a mudança organizacional bem-sucedida está enraizada no comprometimento. Segundo esse autor, qualquer projeto de mudança só terá êxito se os participantes principais de uma transição estiverem comprometidos tanto na consecução dos objetivos da mudança quanto em pagar o preço acertado. Segundo ele, um número significativo de fracassos em processos de implantação de mudança em empresas se origina da falta de comprometimento, apresentada de formas diversas, entre elas a apatia. Fazendo referência ao trabalho de Mowday e colaboradores (I982), e ressaltando as controvérsias presentes em torno do assunto, Bastos (I994) relaciona comprometimento organizacional com os sentimentos de lealdade, desejo de permanecer e de se esforçar em prol da organização (segundo MOWDAY e colaboradores, I982:I09):

O vínculo afetivo destaca a natureza emocional que pode unir indivíduo e organização, em função do atendimento de expectativas e necessidades pessoais. Expressa-se por meio dos sentimentos de gostar, sentir-se leal, desejar se esforçar em prol da organização. 
Identificado e utilizado sob um variado número de conceitos e de instrumentos, porém adequado para a compreensão do comportamento organizacional, o termo comprometimento possui focos diversos no mundo do trabalho, que podem ser alvos de reações ou atitudes do trabalhador, e traz consigo um grande número de estudos que buscam explorar o vínculo do trabalhador com aspectos do seu contexto de trabalho. A permanência ou não no emprego, o absenteismo e a produtividade têm sido vistos como conseqüência do grau de comprometimento do empregado.

O comprometimento, entendido como o vínculo do trabalhador com aspectos de seu trabalho, tem sido analisado sob diversos focos. Cada foco constitui uma tradição de pesquisa própria que, entretanto, não se distribui de forma homogênea (BASTOS, I994). Nesse sentido, por exemplo, Morrow apresenta em dois momentos (1983 e I993) propostas de vinculações do trabalhador de acordo com focos diferenciados. Em sua primeira proposta, o comprometimento é organizado em cinco focos: valores, organização, carreira, trabalho e sindicato. Mais tarde, a autora substitui o foco Sindicato por Ética no Trabalho. Essa alteração se dá, segundo Bastos (I994), pela constatação de sua menor presença, uma vez que a vinculação do empregado parece se restringir mais diretamente à vida do trabalhador em uma organização de trabalho. A proposta apresentada por Morrow em I993 contempla as seguintes formas de comprometimento: ética do trabalho, comprometimento com a carreira/profissão, envolvimento com o trabalho e comprometimento organizacional.

Bastos (I994) identificou padrões de comprometimento de trabalhadores de várias organizações ante os focos organização, carreira e sindicato, por meio de escores gerados por escalas de atitudes. Esse autor apresenta indicadores que demonstram a diferença qualitativa entre esses padrões e fornece subsídios para a constatação de que o trabalhador pode receber demandas de compromissos de diferentes entidades, muitas vezes conflitantes, o que justifica que o comprometimento seja estudado como estrutura ou padrão atitudinal. Ainda conforme esse autor, as duas principais fontes de fragmentação da pesquisa sobre comprometimento se fundamentam nas diversas bases ou processos que afetam a sua natureza, bem como os diversos focos do mundo do trabalho que podem se transformar em alvos de reações ou atitudes do trabalhador. Como as pesquisas sobre comprometimento não se distribuem em todos os focos, a maior concentração encontra-se no comprometimento organizacional. Neste, já é possível verificar o surgimento de meta-análises que sistematizam os principais achados empíricos sobre o tema.

Ao serem analisadas as tipologias de comprometimento utilizadas para diferenciar pessoas e suas relações com a organização, o comprometimento organizacional é caracterizado por Bastos (I994) em cinco dimensões: afetivo/atitudinal, que enfatiza a natureza afetiva do processo de identificação do indivíduo com os 
objetivos e valores da organização; instrumental, que vê o comprometimento como produto das recompensas e dos custos associados à permanência na organização; normativa, na qual o comprometimento é visto como o conjunto de pressões normativas internalizadas para que o indivíduo se comporte de maneira congruente com os objetivos e metas da organização; comportamental, na qual o comprometimento existe em relação a comportamentos ou atos com cognições que fortalecem tais vínculos, como o sentimento de auto-responsabilidade; e sociológica, para a qual o vínculo é conceituado em termos das relações de autoridade que governam o controle do empregador e a subordinação do empregado.

Meyer e Allen (I997) reúnem as três correntes predominantes nas abordagens sobre comprometimento organizacional, quais sejam a afetiva, a instrumental e a normativa. Para consolidar a abordagem afetiva, citam o trabalho apresentado por Mowday, Steers e Porter (I979), que definem comprometimento organizacional como o sentimento de aceitação e crença nos valores e objetivos da empresa, quando os empregados se sentem dispostos a exercer um esforço considerável em benefício da organização e também apresentam um desejo de se manter como seus membros. A abordagem instrumental tem origem em Becker (ig6o), que descreve o comprometimento como um conceito que separa formas de ações características de certos tipos de pessoas. A dimensão normativa é apresentada por Wiener (1982), que argumenta que os indivíduos exibem certos comportamentos porque acreditam ser certo e moral fazê-lo, identificando assim uma forma de controle sobre as ações das pessoas.

Segundo Bastos (I994), os estudos sobre comprometimento organizacional, realizados no Brasil, inserem-se na perspectiva afetiva e se centram basicamente na análise dos antecedentes do comprometimento. Tais estudos chegaram a resultados bastante coerentes e ressaltam a importância de variáveis organizacionais, principalmente a oportunidade oferecida para o crescimento e realização profissionais dos empregados, embora as pesquisas geralmente tenham sido desenvolvidas principalmente em uma única organização, no âmbito do setor público, especialmente em empresas e autarquias. Diversos estudos têm sido realizados no Brasil, procurando associar comprometimento e outras variáveis do comportamento humano no trabalho. Oliveira, Lima e Borges-Andrade (I999) relatam correlações positivas entre comprometimento organizacional com a carreira e indicadores de produção científica de pesquisadores. BorgesAndrade e Pilati (200I) analisaram a relação entre comprometimento atitudinal e comportamental, suporte e imagem nas organizações, envolvendo I.495 empregados de 26 organizações. Sugerem esses autores que diferentes imagens organizacionais estão associadas a fatores de suporte distintos e que tais imagens podem predizer os vínculos afetivos do indivíduo com a sua organização, mas não o seu comprometimento comportamental no papel ou extrapapel. 
No que se refere à relação entre burnout e comprometimento, um dos poucos estudos identificados na revisão de literatura realizada para este artigo é o de Wright e Hobfoll (2004), que analisaram as relações empíricas entre as três dimensões de burnout, bem-estar psicológico, comprometimento organizacional e desempenho no trabalho. Esses autores encontraram relações bivariadas entre bem-estar psicológico, comprometimento organizacional e burnout. Identificaram, também, relações negativas entre as três dimensões de burnout e comprometimento.

A liderança é outra variável que vem sendo associada com comprometimento. Diniz e Lemoine (I999), ao estudarem a relação entre estilo de liderança e comprometimento das pessoas com a empresa, encontraram um índice de correlação de o,64, considerado bastante forte pelas referidas autoras. Esse resultado, ainda segundo as autoras, indica que o comprometimento na empresa se constitui numa função do estilo de liderança. Essas autoras investigaram o comprometimento em 22 empresas de médio porte localizadas no Estado da Paraíba e constataram que o comprometimento organizacional é influenciado pelas relações interpessoais, o que quer dizer que essas relações contribuem para dar sentido ao trabalho do empregado e para favorecer o comprometimento na organização. Essa constatação, aliada à ausência de estudos brasileiros que articulem burnout e comprometimento, justifica o presente estudo, uma vez que a síndrome de burnout também contribui para potencializar problemas de relações interpessoais.

\section{METODOLOGIA}

Esta pesquisa considerou como variáveis independentes o comprometimento afetivo e dados demográficos e funcionais dos respondentes, e como variável dependente a síndrome de burnout. Formulou-se uma hipótese composta de duas partes: os gestores da Eletronorte teriam um alto nível de comprometimento afetivo com a Empresa e apresentariam comportamentos típicos da síndrome de burnout, e haveria uma relação positiva entre comprometimento e a referida síndrome. A hipótese foi ancorada nos seguintes pressupostos:

a) a organização pesquisada passou por um processo de reestruturação, no ano de 2000 , tendo reduzido o seu quadro gerencial e implementado um Programa de Demissão Voluntária, sendo possível supor que os gestores que nela permaneceram o fizeram por estarem comprometidos com a Organização;

b) tais empregados, em face do período de declínio organizacional pelo qual a Eletronorte estava passando, na época da pesquisa, estariam sentindo-se incapazes de mudar o curso da história da Empresa e, portanto, estariam predispostos a apresentar sintomas de burnout. 
A pesquisa teve caráter censitário, tendo sido obtidas respostas de 249 gestores da Eletronorte, que representavam 90\% do total de gestores da organização, os quais preencheram um questionário contendo respostas padronizadas com escalas tipo Likert. O questionário era composto de duas partes. A primeira, destinada a identificar os aspectos relativos ao comprometimento organizacional afetivo e à síndrome de burnout, e a segunda buscou coletar dados demográficos e funcionais dos respondentes. Foram, também, entrevistados I 6 desses respondentes, quando se utilizou um roteiro semi-estruturado, com o intuito de melhor compreender os sentimentos, crenças e atitudes em relação à organização e interpretar, com maior profundidade, as tendências observadas nos dados coletados por meio dos questionários. A coleta de dados foi realizada no período de novembro a dezembro de 2000 .

Para identificação dos sintomas relacionados à síndrome de burnout, optouse por aplicar o questionário desenvolvido por Maslach e Jackson em I98I, o qual recebeu tradução, adaptação e validação semântica realizada por Tamayo (I997). O referido questionário é composto pelos fatores Exaustão Emocional, Diminuição da Realização Pessoal e Despersonalização, apresentados em 22 itens relacionados com sentimentos pelo trabalho.

Com referência ao construto comprometimento, utilizou-se o modelo adaptado e validado por Bastos (i994), no que se refere ao comprometimento afetivo. O instrumento é composto de Io itens, fundamentados na conceituação e escala propostas por Mowday et al. (I979). Essa escala, adaptada e validada para o contexto brasileiro por Borges-Andrade e colaboradores (I989), foi considerada por Bastos (I994) como a mais adequada ao tema, em comparação com vários outros instrumentos para mensuração do comprometimento organizacional.

Considerando que os questionários propostos foram elaborados em momentos diferentes, e que continham alterações e adaptações identificadas como necessárias, foram adotadas algumas medidas com o intuito de apurar a precisão do instrumento utilizado nesta pesquisa, que incluiu os dois construtos, de acordo com a seguinte ordem: adequação semântica dos itens do questionário, buscando adequá-los à realidade da empresa pesquisada; verificação da adequação do instrumento, por meio da aplicação de pré-teste em um grupo de $5 \%$ do universo de gestores da Eletronorte; validação semântica realizada com oito gestores, que individualmente analisaram o questionário apresentado. Após as alterações sugeridas, os questionários foram, então, encaminhados aos respondentes, mediante correspondência enviada por malote interno da Empresa, contendo orientações para o seu preenchimento.

Os dados obtidos com a aplicação dos questionários foram submetidos a um programa estatístico, utilizando-se o método parwise. O passo inicial da análise desses dados foi a codificação das respostas e a preparação do banco de dados para processamento no programa SPSS (Statistical Package for Social Sciences, 
versão Io.o), quando, então, foram realizadas análises de correlação, cálculo de confiabilidade das medidas, análises fatoriais de cada instrumento em particular, análise fatorial do conjunto de itens dos instrumentos e ANOVA one-way.

Quanto aos dados qualitativos, as entrevistas foram editadas, foi realizada uma primeira leitura do seu conteúdo, visando a organizar as idéias incluídas nelas, e, em seguida, foram elaborados sumários. Preliminarmente, o conteúdo das entrevistas foi dividido em temas predominantes, que em seguida deram origem a categorias mais abrangentes, de acordo com os discursos dos participantes. Essas categorias deram suporte para a análise dos resultados do estudo, inclusive no que se refere ao aprofundamento dos dados quantitativos. Buscouse, também, proceder a uma interpretação das entrevistas, quando se procurou identificar aspectos simbólicos dos discursos apresentados pelos entrevistados, que pudessem apresentar novas percepções com relação aos construtos pesquisados que não tivessem sido explicitados anteriormente.

\section{RESULTADOS E DISCUSSÃO}

Maslach (I997) ressalta que a síndrome de burnout não deve ser entendida como uma variável dicotômica, do tipo presente ou ausente, mas sim como uma variável contínua que possui níveis alto, moderado e baixo, de acordo com a predominância e freqüência com que o indivíduo se depara com o sentimento relacionado a cada fator da síndrome. Considerando como escores altos os valores superiores ao percentil 67 , escores moderados os valores situados entre o percentil 33 e o percentil 67 e escores baixos os valores inferiores ao percentil 33, a autora esclarece que um alto nível de burnout se apresenta com escores altos nos fatores Exaustão Emocional e Despersonalização e baixos no fator Diminuição da Realização Pessoal, concomitantemente. Ao contrário, um nível baixo de burnout traz consigo baixos escores nos fatores Exaustão Emocional e Despersonalização e altos escores no fator Diminuição da Realização Pessoal. Finalmente, um nível moderado de burnout se apresenta com escores médios nos três fatores.

Para encontrar os resultados relativos à síndrome de burnout, considerando que os valores da escala utilizada no questionário situavam-se num intervalo de I a 5, inicialmente foram analisadas as médias dos escores de cada fator do conjunto de respondentes e, posteriormente, uma única média, considerando um único fator. Constatou-se que as médias dos fatores Exaustão Emocional e Despersonalização apresentaram-se baixas e as médias do fator Diminuição da Realização Pessoal apresentaram-se altas. Vale ressaltar que a direção dos escores do fator Diminuição da Realização Pessoal é oposta à direção dos escores dos fatores exaustão Emocional e Despersonalização. A seguir, na Tabela I, podem ser observados os resultados encontrados relativos à síndrome de burnout. 


\section{TABELA I}

MÉDIA, DESVIO PADRAO E AMPLITUDE DOS FATORES DE BURNOUT PARA A POPULAÇÃO PESQUISADA

\begin{tabular}{c|c|c|c}
\hline $\begin{array}{c}\text { Estatísticas } \\
\text { fatores }\end{array}$ & $\begin{array}{c}\text { Exaustão } \\
\text { emocional }\end{array}$ & $\begin{array}{c}\text { Diminuição da } \\
\text { realização pessoal }\end{array}$ & Despersonalização \\
\hline Média & 2,30 & 3,98 & 2,08 \\
\hline Desvio padrão &, 61 &, 54 &, 58 \\
\hline Escore mínimo & 1,00 & 2,00 & 1,00 \\
\hline Escore máximo & 4,00 & 5,00 & 4,00 \\
\hline Amplitude & 3,00 & 3,00 & 3,00 \\
\hline
\end{tabular}

Fonte: Dados da pesquisa.

Nota-se que os fatores Exaustão Emocional e Despersonalização obtiveram médias de 2,30 e 2,08, respectivamente, enquanto o fator Diminuição da Realização Pessoal apresentou média de 3,98. Os resultados encontrados indicam que, em termos gerais, os gestores da Eletronorte apresentam nível moderado nos três fatores da síndrome de burnout. Se considerado um único fator, burnout, os resultados se apresentam abaixo da média da escala $(3,0)$, isto é, os gestores da Empresa não apresentam níveis altos da referida síndrome.

Visando a identificar o número de gestores da Empresa que apresentavam a síndrome de burnout nos seus níveis alto, moderado e baixo, utilizou-se procedimento semelhante ao seguido pelos autores do inventário, ou seja, obtenção do somatório dos escores dos respondentes em cada fator, obtido pela soma das respostas dos itens que o compõem; definição do valor dos escores de cada fator que corresponde aos três percentuais da curva normal, quando então foram divididos em níveis alto, moderado e baixo; e criação dos intervalos de qualificação baixa, moderada e alta, por meio do valor mínimo e máximo da somatória dos valores dados pelos respondentes em cada fator. Os resultados obtidos permitem concluir que 69 respondentes, $27,7 \%$ do total, apresentaram os sintomas relacionados com os três fatores da síndrome de burnout com freqüência alta e moderada e I80 respondentes $(72,3 \%)$ apresentaram freqüência baixa.

Farber (I984) constatou um percentual entre I0,3\% e 2I,6\% de incidência de burnout em diversas categorias profissionais nos EUA. Tamayo (I997) identificou um percentual de $16,15 \%$ de incidência alta e moderada de burnout entre profissionais de enfermagem de dois hospitais públicos. Codo e Menezes (I999) identificaram burnout em nível moderado, em uma amostra nacional de aproximadamente 39.000 profissionais atuantes na área de educação com os seguintes resultados em cada um de seus fatores: $37 \%$ de diminuição da realização pessoal; 
I0,7\% de despersonalização e 25,I\% de exaustão emocional. Buik e Thomas (200I) realizaram estudo com I03 gerentes intermediários de hotéis da região de Cincinnati, Estado de Ohio, Estados Unidos, e identificaram altos níveis de burnout em $72 \%, 28,2 \%$ e 40,4\% nos fatores diminuição da realização pessoal, despersonalização, e exaustão emocional, respectivamente. Encontraram, também, esses autores que as gerentes mulheres e gerentes solteiras estão mais sujeitas a burnout do que gerentes homens e gerentes casados, respectivamente.

Quando analisados cada fator individualmente, identificou-se que I5 respondentes, $6,0 \%$ do total, apresentaram alta freqüência relacionada ao fator exaustão emocional; 30, I2,0\% do total, apresentaram alto índice de redução da realização pessoal; I4 respondentes, $5 \%$ do total, apresentaram alto índice de despersonalização (Tabela 2).

\section{TABELA 2}

FREQUENCIA DOS FATORES RELACIONADOS A SINDROME DE BURNOUT ENTRE A POPULACÃO PESQUISADA

\begin{tabular}{l|c|c|c|c|c|c}
\hline \multirow{2}{*}{ Fator } & \multicolumn{2}{|c|}{$\begin{array}{c}\text { Freqüência } \\
\text { alta }\end{array}$} & \multicolumn{2}{c|}{$\begin{array}{c}\text { Freqüência } \\
\text { moderada }\end{array}$} & \multicolumn{2}{c}{$\begin{array}{c}\text { Freqüência } \\
\text { baixa }\end{array}$} \\
\cline { 2 - 7 } & f & $\%$ & $\mathbf{f}$ & $\%$ & f & $\%$ \\
\hline Exaustão & 15 & 6 & 143 & 57 & 91 & 37 \\
\hline Diminuição da realização pessoal & 30 & 12 & 162 & 65 & 57 & 23 \\
\hline Despersonalização & 14 & 5 & 129 & 52 & 106 & 43
\end{tabular}

Fonte: Dados da pesquisa.

Os resultados descritos na Tabela 2 indicam a predominância do fator Diminuição da Realização Pessoal nos níveis alto e moderado entre os gestores pesquisados. Esse fator, denominado também como "falta de envolvimento pessoal no trabalho" (CODO e MENEZES I999), ocorre na relação afeto-trabalho e pode ser entendido como a perda do investimento afetivo. O fato de o gestor não conseguir alcançar os objetivos aos quais se propôs, e de se sentir impotente em "cuidar" dos membros de sua equipe quanto ao futuro no emprego ou à continuidade dos trabalhos, pode gerar um sentimento de impotência, de incapacidade pessoal para realizar algo que tanto sonhou. Esse sentimento pode conduzir o indivíduo a uma auto-análise negativa, particularmente em relação ao seu trabalho, e a uma perda progressiva do sentido do trabalho. Esse fato pôde ser constatado nas entrevistas, como demonstra o seguinte depoimento de um entrevistado: 
Eu acho que o fato de não podermos, ou não conseguirmos atender as expectativas dos colaboradores que trabalham na nossa equipe nos leva a ser mais maleáveis com relação a outras coisas. Leva a gente a amolecer, considerar outras reivindicações menores, a aceitar determinadas coisas que antes não aceitaríamos.

Conforme foi citado anteriormente, diversos estudos têm sido realizados a partir dos anos 80 com o intuito de identificar o nível de comprometimento de indivíduos com a sua organização empregadora, resultando em diferentes formas de mensuração deste construto. Bastos (1994) utilizou escores médios de três medidas de comprometimento, com escalas variando de i a 7. No citado estudo foi utilizada a seguinte convenção: escores superiores a 5 foram tratados como elevado comprometimento; entre 4 e 5 , moderadamente positivo; entre 3 e 4 , moderadamente negativo e abaixo de 3 , elevado descomprometimento. Tendo, portanto, como referência os escores sugeridos por esse autor, adotou-se uma equivalência percentual da divisão sugerida, uma vez que o instrumento de pesquisa utilizado no presente estudo continha cinco alternativas de respostas, e não sete como o instrumento utilizado por Bastos (I994). Dessa forma, considerou-se como elevado comprometimento os resultados com escores entre 4 e 5; como moderadamente positivo os valores situados entre 3 e 4 ; moderadamente negativo, entre 2 e 3 ; e elevado descomprometimento entre i e 2 . Foi encontrado um escore médio geral de comprometimento, entre os respondentes, de 4,05, com desvio padrão de 0,54, resultado este que pode ser considerado como elevado comprometimento.

No que se refere à escala de mensuração do comprometimento organizacional, faz-se importante lembrar que os seus itens são resultantes de estudos de validação do OCQ (organizational commitment questionaire) proposto por Mowday et al. (I979), com escala validada e testada em sua confiabilidade ao longo dos anos por diversos autores. No Brasil, quando a escala foi validada por Borges-Andrade et al. (I989), os autores encontraram coeficiente de confiabilidade (alfa de Cronbach) de ,85. Após excluir os itens referentes às intenções comportamentais, Bastos (I994) encontrou um coeficiente de confiabilidade de ,88 e um eigenvalue de 6,I3. No presente estudo este coeficiente foi de ,8I, com eigenvalue de 3,92.

Paz e Martins (2000), ao pesquisarem a variação do nível de comprometimento organizacional entre o antes (I995) e depois (I998) de um processo de mudança organizacional ocorrido em uma empresa pública federal, encontraram escores considerados altos e positivos, quais sejam, em uma escala de I a 7, identificaram médias de 5,38 (73\%) e 5,35 (73\%) de níveis de comprometimento, respectivamente. Percebe-se, portanto, que a média encontrada nesta pesquisa foi maior do que a encontrada por aqueles autores. Ainda para efeito 
de comparação, encontram-se os estudos de Bastos (2000) desenvolvidos em duas organizações de distintos segmentos industriais, com o objetivo de analisar os vínculos de trabalhadores ante os focos organização, sindicato e carreira. Neste estudo, ao comparar o comprometimento organizacional, utilizando uma escala de I a 7, em uma amostra de I.678 trabalhadores, o autor encontrou os seguintes escores referentes ao comprometimento organizacional: 32,I\% apresentaram um índice de comprometimento de 5,95 (85\%); 28,7\% um índice de 5,33 (76\%); 20,9\% demonstraram um índice de 3,64 (52\%); e I8,4\% apresentaram um comprometimento organizacional de 4,27 (6r\%).

Barbosa e Faria (2000) argumentam que ao se considerar a organização como um conjunto complexo e contraditório de sujeitos e grupos que possuem aspirações, experiências, valores e interesses diferenciados, a idéia de um comprometimento genérico com a organização pode tender a se transformar em algo teórico e empiricamente inconsistente, uma vez que as atividades, as metas e os objetivos a serem alcançados estarão vinculados a estratégias operacionais, próximos à realidade do sujeito, mais relacionados a seu departamento ou setor de trabalho e muitas vezes bastante distanciados de metas organizacionais, tais como lucratividade, reconhecimento da sociedade, produtividade etc. Essa argumentação pôde ser identificada nas entrevistas realizadas, quando alguns entrevistados, ao serem indagados se identificavam os objetivos e as metas propostas pela empresa, responderam:

Elas são desvinculadas do meu trabalho. O que acontece é que eu não as conheço com antecedência. Como a área em que eu trabalho é uma área que atinge toda a empresa, eu recebo as solicitações e aí eu as insiro dentro das metas da empresa. É assim que eu conheço as metas da empresa.

Eu conheço os objetivos e metas da minha regional (unidade descentralizada). Mas não conheço os objetivos e metas da Eletronorte como um todo.

Foram realizadas análises de correlação de Pearson e de Sperman, visando a identificar as relações entre variáveis demográficas e funcionais, comprometimento e síndrome de burnout. Inicialmente foi considerado isoladamente cada um dos três fatores de burnout (variável dependente), os quais apresentaram as seguintes correlações (p<o,oI) com comprometimento (variável independente): exaustão emocional, correlação negativa $(-, 5 \mathrm{II})$, realização pessoal, correlação positiva $(, 534)$, e despersonalização, correlação negativa $(-, 648)$. Ao ser analisada a variável burnout como um único fator, em relação ao comprometimento, encontrou-se um coeficiente Beta de -700 e um nível de significância de ,००০, permitindo inferir que, quanto maior o comprometimento organizacional afetivo, 
menor o nível de burnout. Wright e Hobfoll (2004) também encontraram relação negativa entre comprometimento e burnout.

Identificou-se correlação negativa entre o tempo de gerência e a síndrome de burnout (três fatores conjuntos), ou seja, quanto maior o tempo de gerência, menor a incidência da síndrome $(-=-165$, sig $=, 049)$. Talvez o maior tempo de empresa dê ao gestor a maturidade necessária para não se deixar abater com os fatos negativos que tenham sido gerados externamente ou com o sentimento de impotência para mudar o ambiente externo. Foi encontrada uma correlação positiva entre a lotação dos gestores e a síndrome de burnout ( $-=-150$, sig = ,023), mostrando que os gestores lotados na sede da Empresa apresentam maior incidência de burnout. Esse é um outro aspecto que merece ser considerado com atenção, pois, ao se constatar que as áreas responsáveis pela gestão corporativa da Empresa encontram-se em sua sede, em Brasília, talvez uma maior conscientização dos gestores sobre a impossibilidade de atuar ante as necessidades funcionais de seus colaboradores seja uma das causas de maior incidência de burnout entre esses respondentes. Foi encontrada, também, uma correlação positiva com o fato de o respondente ser casado e a síndrome de burnout (_ = ,I93, sig. = ,oI9). Talvez a insegurança com relação ao futuro, à estabilidade financeira, à garantia de manutenção da família, provocada pelas constantes mudanças do ambiente externo, esteja potencializando o estado de sofrimento do gestor, trazendo consigo, em um primeiro momento, reações características da referida síndrome.

Os resultados apresentados confirmaram, apenas parcialmente, a primeira parte da hipótese. Os gestores pesquisados apresentaram elevados níveis de comprometimento afetivo com a organização em que trabalham, sendo que 69 respondentes, $27,7 \%$ do total, apresentaram os sintomas relacionados com os três fatores da síndrome de burnout com freqüência alta e moderada, e I8o respondentes $(72,3 \%)$ apresentaram freqüência baixa. A segunda parte da hipótese, no entanto, foi rejeitada, já que os resultados mostraram uma correlação negativa entre comprometimento e burnout. Ou seja, quanto mais comprometidos, menor o índice de burnout entre os gestores da organização pesquisada.

\section{CONCLUSÕES}

Os objetivos da pesquisa foram alcançados, demonstrando que os princípios teóricos relacionados com a síndrome de burnout e o comprometimento organizacional afetivo têm um correspondente empírico. Os resultados encontrados indicaram que, em termos gerais, os gestores da empresa pesquisada apresentam nível médio da síndrome de burnout, sendo que $27,7 \%$ dos pesquisados apresentaram índices altos ou moderados nos três fatores da síndrome, 
havendo predominância do fator Diminuição da Realização Pessoal nos níveis alto e moderado. Quanto ao comprometimento organizacional afetivo, constatou-se um elevado comprometimento entre I54 pesquisados, ou seja, 6I, $8 \%$ do total, e moderadamente positivo entre 90 pesquisados, representando 36 , I4 \% do total, permitindo inferir que os gestores pesquisados são altamente comprometidos com a organização em que trabalham. Foi possível constatar, também, que existe correlação negativa entre o comprometimento e a síndrome de burnout.

Quanto ao índice de burnout encontrado entre os pesquisados, embora não elevado, resgatam-se as observações de Maslach (1997), que alerta para o fato de que está aumentando o período de tempo que as pessoas dedicam ao trabalho e que a sobrecarga de trabalho talvez explique a divergência entre a pessoa e o trabalho, uma vez que ela deve fazer muito, em pouco tempo, com recursos escassos. Parece ser este o momento das organizações se atentarem para esse fato. Entretanto, para que estudos mais aprofundados sejam desenvolvidos, recomenda-se que, em futuras pesquisas, os dados sejam complementados com informações sobre o estado físico e emocional dos pesquisados.

O questionário utilizado para a realização da pesquisa mostrou-se adequado para a identificação da presença dos fatores da síndrome de burnout e do nível de comprometimento organizacional afetivo. Recomenda-se analisar, com maior profundidade, uma variável que apresentou carga fatorial abaixo de $0,30-\mathrm{eu}$ me importo realmente com o que está acontecendo com alguns dos colaboradores da minha equipe - e duas outras variáveis que se mostraram híbridas - trabalhar diretamente com pessoas me deixa muito estressado e trabalhar com pessoas o dia inteiro é realmente um grande esforço para mim.

Considerando que esta pesquisa foi aplicada poucos meses após a implementação, pela Eletronorte, do Programa de Demissão Voluntária, os resultados encontrados podem ter sido influenciados por essa decisão da empresa. Os gestores pesquisados, em sua maioria, se disseram sobrecarregados de trabalho. A distribuição espacial da Eletronorte inviabilizou a participação de representantes de todas as suas unidades nas entrevistas realizadas e, por isso, algumas peculiaridades específicas das diversas unidades podem não ter sido consideradas. Ressalta-se que o presente estudo diz respeito a uma única organização do setor elétrico, não podendo, por isso, os resultados alcançados ser extrapolados a todo o setor. Sugere-se que estudos complementares sejam desenvolvidos, objetivando a ampliação do conhecimento sobre os temas aqui desenvolvidos.

Considerando as conclusões do presente estudo, sugere-se como agenda de futuras pesquisas:

a) o desenvolvimento de estudo mais apurado quanto aos fatores da síndrome de burnout. Nessa linha, sugere-se testar as hipóteses de um único fator, como propõe Zohar (I997), e de cinco fatores, como proposto por Densten (200I); 
b) o desenvolvimento de pesquisa mais aprofundada sobre a relação entre comprometimento organizacional afetivo e burnout, com o intuito de verificar, por exemplo, os componentes comuns entre realização pessoal e comprometimento;

c) a replicação desta pesquisa em outros contextos organizacionais, visando a ampliar o poder de generalização dos resultados obtidos. Recomenda-se, em um primeiro momento, que seja realizada nova pesquisa na Eletronorte, considerando a sensível mudança que ocorreu no setor elétrico brasileiro, bem como no corpo diretivo da empresa e dos seus gestores, após a mudança do governo federal, ocorrida em janeiro de 2003 . Recomenda-se também que sejam desenvolvidas pesquisas em outras organizações estatais que estejam passando por processos de mudança para que se possa, em seguida, ampliá-las a órgãos públicos em geral e a empresas privadas.

Por ser este um estudo pioneiro no Brasil, em se tratando da identificação da relação entre a síndrome de burnout e comprometimento organizacional afetivo, acredita-se que o presente estudo tenha contribuído para a redução de algumas lacunas empíricas nesta área, bem como colaborado com a organização pesquisada, visto que esta poderá, apoiada nos resultados aqui relatados, desenvolver programas com o intuito de reduzir o nível da referida síndrome entre seus gestores.

\section{REFERÊNCIAS}

ASHFORTH, B. E.; LEE, R. T. Burnout as a process: comentary on Cordes, Dougherty and Blum. Journal of Organizational Behavior, v. I8, p. 703-708, I997.

BARBOSA, S. de L.; FARIA, J. H. Comprometimento: uma avaliação crítica sobre a práxis organizacional. EnANPAD, 24, 2000, Florianópolis, Anais Eletrônicos..., Florianópolis: ANPAD, 2000.

BASTOS, A. V. B. Comprometimento no trabalho: a estrutura dos vínculos do trabalhador com a organização, a carreira e o sindicato. Tese (Doutorado em Psicologia)-Universidade de Brasília. Instituto de Psicologia, Brasília. I994.

.Comprometimento no trabalho: os caminhos da pesquisa e os seus desafios teórico-metodológicos. In: TAMAYO, A.; BORGES-ANDRADE, J. E.; CODO, W. (Org.). Trabatho, organizações e cultura. São Paulo: Cooperativa de Autores Associados, I996.

Padrões de comprometimento com a profissão e a organização. O impacto de fatores pessoais e da natureza do trabalho. Revista da Administração, v. 35, n. 4, p. 48-6o, out./dez. 2000.

BASTOS, A. V. B.; ROCHA, A. S. C. Comprometimento do empregado e contextos organizacionais em mudança: o caso do Banco do Brasil. EnANPAD, 23, I999, Foz do Iguaçu. Anais Eletrônicos... Foz do Iguaçu: ANPAD, I999. 
BECKER, H. S. Notes on the concept of commitment. The American Journal of Sociology, v. 66, p. 32-40, I960.

BORGES-ANDRADE, J. E.; PILATI, R. Comprometimento atitudinal e comportamental: relações com suporte e imagem nas organizações. Revista de Administração Contemporânea, v. 5, n. 3, p. 85-IO6, 200 I.

BUICK, I.; THOMAS, M. Why do middle managers in hotels bur nout? International Journal of Contemporary Hospitality Management, v. I3, n. 6, p. 304-209, 2001.

CODO, W. Educação, carinho e trabalho. Petrópolis: Vozes, I999.

CONNER, D. R. Gerenciando na velocidade da mudança. Rio de Janeiro: Infobbok, I995.

CORDES, C. L.; DOUGHERTY, T. W.; BLUM, M. Patterns of burnout among managers and professional: a comparison of models. Journal of Organizational Behavior, v. I8, p. 685-70I, I997. DENSTEN, I. L. Re-thinking burnout. Journal of Organizational Behavior, v. 22, n. 8, p. 833847,2001 .

DINIZ, M. A. S.; LEMOINE, C. Em matéria de comprometimento na empresa, são os valores individuais que contam. EnANPAD, 23, I999, Foz do Iguaçu. Anais Eletrônicos... Foz do Iguaçu: ANPAD, I999.

JACKSON, S. E.; SCHWAB, R. L.; SCHULER, R. S. Toward an understanding of the burnout phenomenon. Journal of Applied Psychology, v. 7I, n. 4, p. 630-640, I986.

LEE, R. T.; ASHFORTH, B. E. On the meaning of Maslach's three dimensions of burnout. Journal of Applied Psychology, v. 75. n. 6, p. 743-747, I993.

.A meta-analytic examination of the correlates of the three dimensions of job burnout. Journal of Applied Psychology, v. 81, n. 2, p. I23-133, I996.

LEITER, M. P.; MEERCHAN, K. N. Work-unit structure and processes and job-related stressors as predictors of managerial burnout. Journal of Applied Psycology, v. 21, n. 22, p. I83II847, I986.

MASLACH, C.; LEITER, M. P. The truth about burnout: how organizations cause personal stress and what to do about it. San Francisco: Jossey - Bass Publishers, I997.

.Burnout: a social psychological analysis. The burnout syndrome - Current research, theory, interventions. Illinois: London House Press, 1997.

MEYER, J. P.; ALLEN, N. J. Commitmente in the workplace: theory, research and apllication. London: Sage, I997, apud BASTOS, A. V. B.; ROCHA, A. S. C. Comprometimento do empregado e contextos organizacionais em mudança: o caso do Banco do Brasil. EnANPAD, 23, I999, Foz do Iguaçu. Anais Eletrônicos... Foz do Iguaçu: ANPAD, I999.

MORROW, P. C. Concept of redundancy in organizational research. The case of work commitment. Academy of Management Review, v. 8, p. 468-500, I983.

.The theory and measurement of work commitment. Monographs in Organizational Behavior and Industrial Relations. Connecticut: JAI Press Inc., v. 15, I993.

OLIVEIRA, M. A. P. S.; LIMA, S. M. V.; BORGES-ANDRADE, J. E. Comprometimento no trabalho e produção científica entre pesquisadores brasileiros. Revista de Administração, v. 34, n. 3, p. I2-20, I999.

PAZ, M. G. T.; MARTINS, J. L. T. P. Poder e comprometimento em tempo de mudança organizacional: estudo de caso de uma empresa pública de serviços de informática. Revista de Administração, v. 35, n. 4, p. 6I-7I, 2000.

SABATOVSKI, E.; FONTOURA, I. P. Legislação previdenciária. Curitiba: Juruá, 200 I. 
TAMAYO, M. Relação entre a síndrome de burnout e os valores organizacionais no pessoal de enfermagem de dois hospitais públicos. Dissertação (Mestrado em Psicologia)-Universidade de Brasília. Instituto de Psicologia, Brasília, I997.

WRIGHT, T. A.; HOBFOLL, S. E. Commitment, psychological well-being and job performance: an examination of conservation resources (COR) theory and job burnout. Journal of Business and Management, v. 9. n. 4, p. 389-406, 2004.

ZOHAR, D. Predicting burnout with a Hassle-based measure of role demands. Journal of Organizational Behavior, v. I8, p. IOI-II5, I997.

T R A MITA Ç $\tilde{A}$ O

Recebido em 03/05/2004

Aprovado em 07/01/2005 